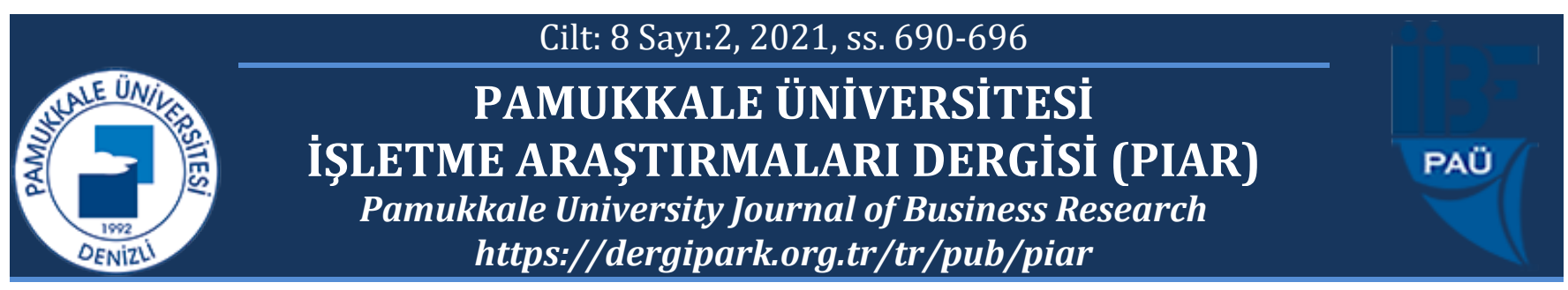

\title{
Değişimler Karşısında Yönetici Yetersizliği ve Yönetim Paradoksu
}

Managerial Incompetence and Management Paradox in the Face of Changes

\section{Feyzullah EROĞLU1*}

\author{
1Pamukkale Üniversitesi, İ̈BF, feroglu@pau.edu.tr, https://orcid.org/0000-0001-7462-8851 \\ *Yazışılan Yazar/Corresponding author
}

Makale Geliş/Received: 19.10.2021

Öz

Toplu olarak yaşayan diğer canllların birlikteliği, büyük ölçüde içgüdüsel ve biyolojik süreçlere bağhl olmakla birlikte, insanlardaki grup halinde ya da toplum olarak yaşama arzusunun asıl belirleyici etkeni, kişilerin istemsiz ya da iradi olarak başka insanlara olan karşılıklı bağımlılık ve etkileşim ihtiyaçlarıdır. Insanlar, diğer canlılara göre daha üstün bir varlık olarak yaratılmış olsa da, her daim kendi türdeşiyle iletişim ve iş birliği içinde olma zorunluluğu oldukça güçlü bir motivasyondur. Insanlar için etkili, verimli ve erdemli bir hayat inşa etme, asla tek başına gerçekleştirilebilir bir durum olmayıp, başarll ve uygun iş birliği sistemleri aracılığıyla mümkün olabilmektedir. İnsanlarm, geleneksel ve kurumsal olarak birbirleriyle çeşitli iş birliğ $i$ sistemleri oluşturmalarının sürdürülebilirliği ise başarılı yönetim süreçleri sayesinde gerçekleşmektedir.

Anahtar kelimeler: Yönetim Süreci, Liyakat Sistemi, Yönetici Yetersizliği, Yönetim Paradoksu, Yönetim Krizi

JEL kodları: M10, H12, L20
Makale Kabul/Accepted: 08.12.2021

\begin{abstract}
Although the coexistence of other living creatures is largely dependent on instinctive and biological processes, the main determining factor of people's desire to live in groups or as a society is their involuntary or voluntary need for interdependence and interaction with other people. Even though humans were created as superior beings compared to other living things, the necessity of communicating and cooperating with their fellow humans at all times is a very strong motivation. Building an effective, productive and virtuous life for people is never a situation that can be accomplished alone, but is possible through successful and appropriate cooperation systems. The sustainability of creating various cooperation systems with each other, both traditionally and institutionally, is achieved through successful management processes.
\end{abstract}

Keywords: Management Process, Merit System, Manager Incompetence, Management Paradox, Management Crisis

JEL codes: M10, H12, L20 


\section{GİRIŞ: YÖNETIM SÜRECI BİR LIYAKAT SISSTEMİDIR}

İnsanlar, varlıklarını sürdürebilmek için başka insanların desteğine ve iş birliğine zorunlu olarak muhtaç olan sosyal bir varlıktır. Tarihsel süreç içinde nicel olarak sayıları ve nitel olarak sosyo-ekonomik işlevleri değişse de devlet, ordu, yargı, eğitim ve din gibi makro ölçekteki kurumlar ile işletmeler, vakıflar, dernekler ve siyasi partiler gibi mikro ölçekteki kuruluşlar, insanlığın asla vazgeçemediği iş birliği sistemleridir. Her iş birliği sisteminin oluşumu ve sürdürülebilirliği, birden fazla insanın önceden belirlenmiş olan amaçlar doğrultusunda, diğer insanlarla uzlaşmalarına bağlıdır. Kalıcı bir iş birliği sisteminin katılımcıları arasında zoraki ya da karşılıklı rızaya dayalı bir ast-üst ilişkisi yani bir yönetim sürecini gerekmektedir. Birer yönetim süreci olarak iş birliği sistemleri, birçok iş ve görevi, bunları layıkıyla yapabilecek insan kaynağı ile çalışanların iş ve görevlerini etkili ve verimli bir şekilde yapılabilmeleri için dengeli bir yetki ve sorumluluk dağılımını zorunlu kilmaktadır.

Kurum ve kuruluşların yönetim sürecindeki her iş ve görevin, etkili ve verimli bir şekilde yapılabilmesi, bunları üstlenecek kişilerin, belirli yetenek, bilgi, beceri ve bazı kişilik niteliklerine sahip olmaları gerekir. İş birliği sistemi olarak yönetim süreçlerinde rol alan kişilerin fiilen sahip oldukları yetenek, bilgi, beceri ve kişilik nitelikleri ile bu işlerin ve görevlerin gerektirdiği yetenek, bilgi, beceri ile kişilik niteliklerinin birbirlerine denk düşmesi beklenir. Çünkü, herhangi bir yönetim sürecinde yer alan kişinin başarısı, bu niteliklere fiilen sahip olduğu liyakat ölçüsünde gerçekleşir. Nasıl insanlar, bedensel ve fizyolojik yapılarının sahip olduğu kapasitenin üstünde fiziksel eylemleri gerçekleştiremezlerse; bir yönetim sisteminde rol alan kişiler de, üstlendikleri iş ve görevin gerektirdiği liyakate sahip değillerse; sorunları çözemezler, işlerini başarılı bir şekilde yapamazlar ve değişimlerin gerektirdiği uyumu gösteremezler.

Yönetim süreçlerinde, temel amaçlara ulaşılması ve başarılı olunması için her bir çalışanın kendisiyle ilgili görevi tam olarak yapması ve başarılı olması beklenir. Sistematik bir oluşum olarak yönetim sürecinde yer alan kişilerin üstlendikleri iş ve görevlerin birbirini tamamlayıcı özelliğinden dolayı birkaç kişinin etkili ve verimli olması yeterli olmamaktadır. Her bir çalışan başarılı olmalı ki, yönetsel etkinlikler başarılı sonuçlar verebilsin. $\mathrm{Bu}$ bağlamda, yönetim sürecinde rol alan kişilerin, üstlendikleri iş ve görevleri, birbiriyle anlamlı bir bütün oluşturacak biçimde başarmalarından ve karşılaşacakları sorunlara yeterli ölçüde çözüm bulmalarından büyük ölçüde "yöneticiler" sorumludur. Yönetici kadroların temel işlevi, bir bütün olarak kurum ve kuruluşlardaki bütün çalışanların iş ve görevlerini etkili ve verimli bir biçimde yapmalarını sağlamaktır. $\mathrm{Bu}$ bağlamda, yönetici konumundakilere, böyle kapsamlı bir iş gördürme sorumluluklarından dolayı astlara göre daha fazla yönetim yetkisinin verilmesi zorunluluğu vardır. Başka insanlara "iş gördürmek", bir anlamda onların yeteneklerini, bilgilerini ve kişiliklerini de yönetmek anlamına gelmektedir. Bir yönetim sistemindeki yönetici kadronun, birbirlerinden farklı yetenek, bilgi ve kişiliklere sahip çalışanları, birbirleriyle çelişmeden ve çatışmadan, işlerin zamanında ve tam olarak yapmalarını sağlayabilmek için bütün çalışanlara göre, çok daha fazla yönetme yetenek, bilgi ve becerisi olmalıdır. Bir yönetim sistemindeki mevcut yönetim otoritesinin (yani yetki ve sorumluluğunun), büyük ölçüde tepe yönetim kademelerinde toplanmış olduğu otoriter ve merkeziyetçi örgütlerdeki yöneticiler, yönetimle ilgili kararların çoğunu kendileri alacakları için özellikle bu yöneticilerin yetenek, bilgi ve 
becerilerinin daha yüksek olması sistemin sorunsuz işlemesi bakımından son derece önemlidir. Bu yüzden, otoriter ve merkeziyetçi yönetim sistemlerinde, yer alan yöneticiler, sahip oldukları yetki ve sorumluluk ölçüsünde daha yüksek bir liyakat ve ehliyete sahip olmalıdir.

\section{YÖNETIM SÜRECININ ÖZÜ İNSAN KAYNAĞINDANDIR}

Bütün yönetim süreçlerinin asli temeli, "insan” öğesine dayanmaktadır. Yönetim etkinlikleri ile ilgili yapılan en geçerli tanım, yönetimin "belirli amaçlara başka insanlar aracılığıyla ulaşılması" şeklindedir. Yönetim sürecinin bütün öğeleri (söz gelimi, bina, sermaye, teknoloji v.b.g.) son derece nitelikli olsa dahi, bu sistemi işletecek ve çalıştıracak olan yönetimin "insan kaynağı", üstlenmiş oldukları iş ve görevin gerektirdiği düzeyde yetenekli, bilgili ve deneyimli değillerse, etkili ve verimli bir yönetimin gerçekleştirilmesi mümkün değildir. $\mathrm{Bu}$ çerçevede, özellikle başka insanların hayatını çok yakından ilgilendiren kararları almak ve yürütmek üzere seçilmiş veya atanmış olan kişilerin sahip oldukları yetenek, bilgi ve deneyim ile o iş ve görevin etkili ve başarılı bir şekilde yapılabilmesi için gerekli olan yetenek, bilgi ve deneyim düzeyi birbirine denk olmalıdır. Ĕ̆er, çalışan iş görenlerin sahip oldukları yetenek, bilgi ve deneyim, seçildikleri ya da atandıkları iş ve görevin gerektirdiğinden açık ara yüksek ise o zaman yetişmiş-vasıflı insan kaynağı israf ediliyor demektir. Ĕger, çalışan iş görenlerin sahip oldukları yetenek, bilgi ve deneyim, seçildikleri ya da atandıkları iş ve görevin gerektirdiğinden açık ara düşük ise o zaman da bu dengesizlik hali, yetersiz ve vasıfsız kişilerin çok önemli karar ve yönetim birimlerini acımasızca işgal etmesi anlamına gelir. Uygar toplumlarda, çeşitli psikoteknik yöntemler kullanılmak suretiyle iş ve görevlerin tanımları, şartnameleri ve gerekli vasıf düzeyleri daha önceden tespit edilmekte ve bu görevleri üstlenecek yöneticilerin belirlenmesi, büyük ölçüde akılcı ve bilimsel yöntemlerin kullanımına bağlı olarak liyakat ve ehliyet ilkelerine göre yapılmaktadır. Akılcı ve bilimsel zihniyet ile yüksek kültürün egemen olduğu, yönetilenlerin yönetici kadrolar hakkında "biatçı" bir anlayış yerine bilinçli ve sorgulayıcı bir tavır geliştirdikleri uygar yönetim sistemlerinde, bulundukları iş ve görevlerin gerektirdiği liyakat ve vasıflara sahip olan yöneticilerdir. Bu görevliler, iş ve görevleriyle ilgili değişimlerin ortaya çıkardığı yeni durum ve şartlara hızlı uyum gösterme konusunda son derece duyarlı ve kendilerini yenilemeye yatkın kişilerdir.

\section{YÖNETIM DENGESININ BOZULMASI VE YÖNETIMM PARADOKSU}

Yönetim ve organizasyon teorilerinde, ister makro isterse mikro ölçekteki örgütlenmeler düzeyinde olsun, bütün yönetim süreçleriyle ilgili modellerde, her çalışanın ideal ölçüde etkili ve verimli olması bakımından üstlendikleri işlerin gerektirdiği yetenek, bilgi ve bazı kişilik nitelikleriyle donanımlı oldukları varsayılır. Ayrıca, "emaneti ehline vermek", İslâmiyet ile birlikte birçok din ve felsefi sistemlerin temel öğretileri arasındadır. Ancak, temel öğretilerin iman esasları, yönetici sınıfın tutkuları ile çok yönlü kültürel sapmalar yüzünden çoğunlukla yaşanan hayata pek yansımaz. Bu kapsamda, fiili durumdaki iş ve görevlere insanların yerleştirilmesi ya da etkili göreve yükseltilen kişilerin seçimiyle ilgili işlemlerde, "emaneti ehline vermek" yerine, çoğunlukla yakınlık, yandaşlık, particilik, kayırmacılık, yağcılık, rüşvetçilik ve çetecilik gibi uygulamalara daha sık rastlanmaktadır.

Akılcı ve bilimsel zihniyetten uzak, popüler kültür taşıyıcısı, popülist ve yağmacı siyaset anlayışı doğrultusunda tutucu, ganimet düşkünü, rant tutkusu yüksek ve despotik 
eğilimlere sahip olan toplumsal yapılardaki yönetim birimleri, daha işin başında büyük ölçüde "yetenek", "bilgi" ve "deneyim" konusunda dehşetli bir "iş-iş gören" dengesizliğine sahiptirler. Henüz sosyolojik olarak "millet" olma bilincine ulaşmamış olan bu topluluklar, zihniyet dünyaları itibarıyla etnik, dinsel, mezhepsel, cemaatçi, parti yandaşlığı ve hemşericilik gibi çeşitli alt kimlik kalıplarından dışarıya çıkamayan kişi ve gruplardan oluşmaktadırlar. Popülist siyasetin tercihleri doğrultusunda şekillenen bu yönetim yapılarındaki, çoğu yönetim birimlerine, iş ve görevlere en layık ve ehil olanlar değil, çoğunlukla "bizden olsun, çamurdan olsun" anlayışı sonucunda "bizden olanlar" yerleştirilir. Ayrıca, yolsuzluk ekonomilerinin ve ganimet kültürünün baskın olduğu toplumlardaki yönetim birimlerine, özellikle "akçeli" iş ve görevlere yerleştirme ve atamalar, çoğunlukla "rüşvet" karşılığında adeta "ihale" edilir; kim daha fazla "rüşvet" verirse mevki ve makam onların olur. Bulundukları mevki ve makamları hak etmeyen ve sübjektif ölçütlerle oralara yerleşen yönetici kadrolar, "işgal" ettikleri iş ve görevler bakımından çoğunlukla yeteneksiz, bilgisiz ve deneyimsizdirler. Ancak, "emre hazır" kişiler olup, yaptıkları işin yasal dayanağının olup olmadığını bile umursamazlar.

Açık, sivil ve uygar toplumlardaki yönetim kültürü, "yetki - sorumluluk denkliği" bağlamında büyük ölçüde yönetim otoritesini, alt kademelerine doğru genişletmesine karşılık; kapalı, yarı resmi ve cemaatçi toplumlardaki yönetim kültürü, hem yönetim otoritesini en tepenin tekeline bırakır, hem de üst kademe yöneticiler yönetim otoritesinin neredeyse bütün "yetkilerini" kendilerinde toplarken, "sorumlulukları" da alt kademe çalışanlarına doğru kaydırırlar. Böylece, otoriter ve despotik yönetim kültürünün egemen olduğu toplumsal süreçlerde görülen bu dengesizlik, temel yönetim düşüncesinin "yetki ve sorumluk denkliği" paradigmasına tamamen aykırı bir uygulamadır. Bu durumda, karar alma, iş yapma, sorun çözme, yenilik yapma ve değişimlere hızla uyum sağlama konusunda son derece yetenekli, bilgili ve deneyimli olunması gereken görevlerde, yetersiz ve liyakatsiz kişilerin hem de aşırı yetkiyle donatılmış olması, yönetim düşüncesinin bütünlüğünün bozularak dehşetli bir yönetim çelişkisinin ve paradoksunun ortaya çıkmasına yol açmaktadır.

Belirli amaçlara, başka insanlar aracılığıyla ulaşma eylemi olan yönetim etkinlikleri, bu işlevini etkili ve verimli bir şekilde yerine getiremiyorsa, bu durum bir yönetim krizi sayılır. Bütün toplumsal süreçlerin yönetimi, çok sayıdaki alt-sistemlerin, alt- üst-sistem mantığ1 içinde birbiriyle bağlantılıdır ve karşılıklı etkileşim düzeninde gerçekleşir. Yönetim sisteminin çok sayıdaki alt sistemlerine ilişkin yönetim birimlerinde ortaya çıkan ve düzeltilmeyen bazı bozulmalar, zaman içinde bütün yönetim sisteminin işlevsizliğine yol açmak suretiyle derin bir krizinin yaşanmasına ortam hazırlar. Yönetim, yönetici ve yönetilen kişiler aracılığıyla önceden belirlenen amaçlara etkili ve verimli bir şekilde ulaşamıyorsa, yaşanan derin sorunları çözemiyorsa, değişen durum ve şartlara yeterince uyum sağlayamıyorsa, insanlar birbirlerine ve kurumlara olan güvenlerini kaybediyorsa yönetim krizi aşamasından kaotik bir ortama geçilmiş demektir. 


\section{YETERSİ YÖNETICIILERIN DEĞISŞIME UYUM SORUNU VE DAVRANIŞ KATILAŞMASI}

Yönetim kadrolarının doldurulması, miras yoluyla hanedana dayandırılırsa, silah ve kaba güçle yönetim gasp edilirse, kitle kültürü taşıyıcısı cahil ve açgözlü kitleyi memnun etmek amacıyla popülist (halk dalkavukluğu) istihdam politikası izlenirse, yönetim paradoksu kaçınılmazdır. Kaldı ki, bir toplumda yönetici kadroların yerleştirilmesinde ve atanmasında başlangıçta küçük bir ihtimal sınırlı bir yeterlilik olsa bile, günümüzdeki kapsamlı ve hızlı değişimler karşısında, yetenek, bilgi ve beceri gibi liyakat ölçütleri konusunda güçlü bir zihinsel alt yapısı olmayan yöneticiler, değişime bağlı yeni durum ve şartlar karşısında yetersiz kalacaklardır. Eskiden, çoğunlukla değişimin alanı belirli ve hızı nispeten düşük olmasına karşılık, özellikle 1990'lı yıllardan itibaren küreselleşme sürecinin doğurduğu yenilikler ve değişim dalgaları sonucunda, değişimin kapsamı genişlemiş, kısa sürelerde çok hızlı değişmeler yaşanmaya başlanmıştır. Bu bağlamda, eski durum ve şartlar çerçevesinde şekillenen yönetim yaklaşımları ve alışkanlıkları, yeni durum ve şartları yönetme kapasitesini ve gücünü kaybetmeye başlamıştır. Hiç kuşkusuz hayatın her alanında ortaya çıkan yeniliklerin ve yeni değişim dalgalarının arkasında, yeni bilgi sistemleri vardır; o halde yeni durum ve şartlara hızla uyum sağlayabilecek yönetim anlayışları ve yaklaşımları geliştirmek gerekir. Böyle bir yönetsel uyumun en etkili aracı ve malzemesi, yeni araştırma ve inceleme bulgularına dayanan yeni bilgi dalgasıdır. Yönetim süreçlerine ilişkin yeni kararların alınması ve yönetimin sorun çözme kapasitesinin yükseltilmesi, eski yönetsel alışkanlıklarına takılıp kalmış tutucu yöneticilerin işi değildir. Değişimler karşısında bu uyumu gösterecek olanlar, yine yetenekli, bilgili ve zamanın ruhuna göre hareket edebilecek zihin yapısına sahip olan liyakat ve vasıf düzeyi yüksek olan yöneticilerdir.

Köklü değişimlerden geçildiği zaman, değişime uyum sağlayamayan tutucu kişiler ve gruplar, çoğunlukla uyumsuzluk ve ihtiraslı ruh halleri gibi davranış katılaşması yaşarlar. Kişiler ve gruplar, köklü değişimlere maruz kalıp da gerekli uyumu gösterecek bilgi ve beceriye sahip değillerse giderek özgüven ve özsaygılarını kaybederler. Özgüven ve özsaygılarını kaybeden kişiler ise insan şahsiyetinin bu çok önemli niteliklerinin yerine, kendilerinin ya da başkalarının hiç sorgulama hakkının olmadığını düşündükleri inanç ve dinsel tutumlara sarılırlar. İnanç, tutku ve şevk yoğunluğu genellikle bilgi ve becerinin yerine geçer ve sanal bir özgüven imgesi ortaya çıkar (Hoffer, 2017, s. 8-9). Yetersiz yöneticilerin uyumsuzluk ve başarısızlıklarının doğurduğu kızgınlık, öfke ve otoriterleşme, yönetim davranışlarında aşırı bir katılaşmaya yol açar ve baskıcı uygulamalar ortaya çıkar.

Yönetim zihniyeti itibarıyla henüz rasyonel düşünce aşamasına gelememiş, bireysel irade ve özgürlügünden yoksun olup mensubiyet duyduğu kolektif grupların (söz gelimi, cemaat, tarikat ve birer cemaat- tarikat mensubiyetine dönüşen parti yandaşlığının) belirli yönetim anlayışlarının kalıplarının dışına çıkamayan zayıf karakterli yöneticiler, ister makro isterse mikro ölçekte yönetim birimlerinin başında olsunlar, başında bulundukları yönetim alanını önce bir yönetim krizine, daha sonra da derin ve karmaşık bir yönetim paradoksunun içine sokarlar.

\section{SONUÇ: TÜRK YÖNETIMM DÜŞÜNCESINNIN TEMEL PARADİGMALARINA DÖNÜŞ}

Çevresel değişimler karşısında, küresel ölçekte yaşanmakta olan yönetim krizleri, akıl ve bilim öncülüğünde yönetim sistemleri oluşturmuş toplumlar açısından nispeten kısa 
sürelerde ve hasarsız bir şekilde yönetilebilmektedir. Buna karşılık, toplumların büyük bir kısmında yöneticilerin yetersizliği ve liyakatsizliği, yönetilenlerin aymazlığı ve cahilliği yüzünden son derece başarısız yönetimler, çok büyük acıların yaşanmasına ve kaynakların heba olmasına yol açmaktadır. Yaygın yönetim başarısızlı̆̆ının, her toplumsal kültür açısından kendine özgü birtakım etkenleri olmakla birlikte, yönetici yetersizliği ve yönetilenlerin duyarsızlığının, hemen tamamında ortak olan etken olduğu görülmektedir.

Türk yönetim düşüncesinin çok önemli bir aşamasını temsil eden Göktürk Yazıtlarında, Türk Milleti'nin kaderi ile yöneticilerin nitelikleri arasında doğrudan bir bağlantı kurulur. İkinci Göktürk Devletinin kuruluşunda ve yönetiminde çok etkili bir görev gören Bilge Tonyukuk, yönetim kadrolarında yer alacakların, akıllı, bilge, cesur, deneyimli, kendinden emin ve zamanın en güçlü rakipleri olan Çin'i çok iyi tanıyan kişiler olması gerektiğini önerir. Bilge Kağan Yazıtı'nda, devletin varlığı ile yönetici kadroların nitelikleri özdeş kabul edilmesinden dolayı, iyi kağan ve yöneticilerin, devlet kurup düzeni sürdürürken, kötü kağan ve yöneticilerin düzeni bozarak devletin çöküşüne neden oldukları belirtilir. "Kardeşler ağabeyleri gibi, oğullar babaları gibi yaratılmadıklarından, akılsız kağanlar iş başına gelmiş, yardımcı olarak da akılsız komutanlar seçtiklerinden, düzeni bozmuşlar"dır (Bilge Kağan D 5,6). Bilge Kağan'a göre, devlet yönetiminin başarısı, şans ve hanedan üyeliği gibi sübjektif ölçütlere göre değil, kağanların becerileri, yöneticilerin iyiliği ve halkın tutumuyla ilişkilidir. Birinci Göktürk Devleti'nin yıkılma nedenlerinden birisi, kağan ve yöneticilerin yetersizliği ise ikinci önemli etken olarak halkın tutumu gösterilmiştir. Bilge Kağan, "Ey Türk halkı, sen tok gözlü ve aksisin: Açlığı tokluğu düşünmezsin; bir de doyarsan açlığı hiç düşünmezsin, böyle olduğun için hep mahvoldun ve tükendin" (Bilge Kağan, K 6-7; Kül Tigin, G 8-9) ; "Kanlarınız ırmaklar gibi aktı, kemikleriniz dağlar gibi yığıldı; bey olacak oğullarınız köle oldu, hanım olacak kızlarınız cariye oldu" (Bilge Kağan, D 18-20; Kül Tigin, D 23-24) diyerek, başarısız yönetimden dolayı hem yöneticileri hem de halk1 birlikte eleştirir ( Biçak, 2009, s. 70-73). Türk yönetim düşüncesinin kutup yıldızlarından Herat (Afganistan) doğumlu Ali Şir Nevâyi, “Türkler de yararlansın” diye başladığı ve 1500'de yazdığ1 "Gönüllerin Sevgilisi" adlı eserinde, "Hakanın halkının da, hakanın işine ve tavrına benzeyeceğini; hakan adaletli ise halkın alışkanlığının da adaletli, hakan zulüm üzere ise halkın da zulüm yapma düşüncesinde olacağını; hakan, Müslümanca davranırsa halkın alışkanlıklarının da İslam'a göre, hakan kafir ahlaklı ise halkın fiillerinin de küfür yolunda olacağını" anlatmaktadır (Nevâyi, 2020, s. 34).

Her dönemin geçirdiği değişimler kapsamında ortaya çıkan şartlar ve durumlar ile farklı kültürel ve politik sistemler, o zamanın ruhuna uygun olacak olan yönetim ilişkilerine yeni boyutlar kazandırır. Ancak, her toplumsal kültür için birçok değişim yaşanmasına rağmen bir kısım kültürel genler her daim geçerliliğini ve değerlerini sürdürür. Thomas S. Kuhn'ın belirli teori ve öğretilerin olmazsa olmaz nitelikteki temel şartlarını "paradigma" kavramıyla açılamasından esinlenerek, Bilge Kağan ve Bilge Tonyukuk'un İkinci Göktürk Devletinden, Mustafa Kemal Atatürk'ün Türkiye Cumhuriyet'ine uzanan Türk yönetim düşüncesinin kültür genleri veya kök paradigmaları dört başlık halinde ifade edilebilir: Birincisi, "Kut ve Töre" (adalet) inanc1; ikincisi, "bilgelik"; üçüncüsü, kurultay-kengeş (danışma meclisleri); dördüncüsü, haksız otoriteye "direnme" hakkı (Eroğlu, 2021, s. 4-5). Bu çerçevede, otoriter yönetim kısır döngüsünden çıkmanın ve ağır bir yönetim paradoksundan kurtulmanın en 
akılcı ve bilimsel yolu, yetenekli, bilgili ve iş bilir insan kaynağını liyakat ve ehliyet esaslı istihdam politikasıyla karar merkezlerine ve üretim sürecine dahil etmektir.

\section{KAYNAKÇA}

Bıçak, A. (2009): Türk Düşüncesi I, Kökenler, İstanbul: Dergah Yayınları.

Eroğlu, F. (2021). “Türk Yönetim Düşüncesinin Kök Paradigmaları ve Yönetim Anlayışında Ortadoğulaşma Süreci”, Feyzullah Eroğlu (Ed.), Yönetim Düşüncesi ve Popüler Kültür Altında Örgütsel Davranışlar, İstanbul: Beta Basım Yayım.

Hoffer, E. (2017). Değişim Sancısı (Filiz, B. Çev.), İstanbul: Dergah Yayınları 702.

Nevâyi, A. Ş. (2020). Mahbûbu'l Kulûb (Gönüllerin Sevgilisi) (2. Basım), Hazırlayan: Vahit Türk, İstanbul: Ötüken Neşriyat 